\title{
Independent and Combined Effects of Biological Maturation and aerobic performance on the gross motor coordination in prepubertal girls
}

Ingrid Kelly Alves dos Santos Pinheiro ${ }^{a}{ }^{\infty}$, Leonardo Gomes de Oliveira Luz ${ }^{a, b *}{ }^{\infty}$, Bruno Barbosa Giudicelli ${ }^{\mathbb{D}}$, Douglas Henrique Bezerra Santos ${ }^{\mathrm{a}}$, Braulio Patrick Lima Silva ${ }^{\mathrm{a}}{ }^{\mathbb{C}}$, Arnaldo Tenório da Cunha Júnior ${ }^{\mathrm{a}} \mathbb{C}$, Manuel João Coelho-e-Silva ${ }^{\mathrm{b}} \mathbb{D}$

Keywords:

Biological Maturation; Aerobic Fitness; Motor Competence; Motor Skills.

\begin{abstract}
The present study analyzed the effect of biological maturation on the performance in the test of gross motor coordination in girls, before and after having its effect controlled by body mass index (BMI) and aerobic performance. The sample was composed by 63 pre-pubertal girls (8.08.99 years). The girls who were less advanced in biological maturation presented lower body size and better physical performance in the tasks of walking backward on balance beams $(t=2.706$; $p<0.01 ; d=0.70)$, moving sideways on boxes $(t=2.128 ; p<0.05 ; d=0.48)$, hopping for height on one leg $(t=2.076, p<0.05 ; d=0.54)$ and $20-m$ shuttle run $(t=3.162 ; p<0.05 ; d=0.61)$. The maturation no longer influenced performance in the tasks of gross motor coordination when considering BMI and aerobic fitness.
\end{abstract}

\section{RESUMO}

O presente estudo analisou o efeito da maturação biológica no desempenho em teste de coordenação motora grossa de meninas, antes e depois de ter seu efeito controlado pelo índice de massa corporal (IMC) e pelo desempenho aeróbio. Participaram 63 meninas pré-puberes de 8,0 a 8,99 anos. As meninas menos avançadas na maturação biológica apresentaram menores dimensões corporais e melhores desempenhos físicos nas tarefas de equilíbrio à retaguarda ( $t=2,706 ; p<0,01 ; d=0,70)$, transposição lateral $(t=2,128 ; p<0,05 ; d=0,48)$, saltos monopedais $(t=2,076 ; p<0,05 ; d=0,54)$ e 20 -m shuttle run $(t=3,162 ; p<0,05 ; d=0,61)$. A maturação deixou de influenciar o desempenho nas tarefas de coordenação motora grossa quando levou-se em consideração o IMC e a aptidão aeróbia.

\section{RESUMEN}

El presente estudio analizó el efecto de la maduración biológica sobre el desempeño en prueba de coordinación motora gruesa de niñas, antes y después de tener su efecto controlado por el índice de masa corporal (IMC) y por el desempeño aeróbico. Participaron del estudio, 63 niñas pre-puberes de 8 años. Las niñas menos avanzadas en la maduración biológica presentaron menores dimensiones corporales y mejores desempeños físicos en las tareas de equilibrio a la retaguardia $(t=2,706 ; p<0,01 ; d=0,70)$, transposición lateral $(t=2,128 ; p<0,05 ; d=0,48)$, saltos monopedales $(t=2,076 ; p<0,05 ; d=0,54)$ y $20-m$ shuttle run $(t=3,162 ; p<0,05 ; d=0,61)$. La maduración dejó de influenciar el desempeño en las tareas de coordinación motora gruesa cuando se tuvo en cuenta el IMC y la aptitud aerobia.

\footnotetext{
${ }^{a}$ Federal University of Alagoas, LACAPS, Arapiraca, AL, Brazil.

b University of Coimbra, CIDAF, Coimbra, Portugal.

*Corresponding Author:

Leonardo Gomes de Oliveira Luz

E-mail: leonardoluz@arapiraca.ufal.br
} 


\section{INTRODUCTION}

Motor competence and physical fitness are complex and multidimensional concepts (Luz et al., 2018a). The motor competence of the pediatric population can be characterized in the literature by a variety of terms motor performance, motor ability, motor coordination, motor proficiency, among others (Robinson et al., 2015); while physical fitness is commonly designated as an indicator of readiness for physical performance (Malina et al., 2004).

Motor competence encompasses motor coordination, which can be defined as the harmonious and economic interaction of the musculoskeletal system, the nervous system and the sensory system with the purpose of producing precise and balanced motor actions (Schilling \& Kiphard, 1974). Several test batteries have been used in the evaluation of motor coordination in children (Cools, Martelaer, Samaey \& Andries, 2009). In this context, the Körperkoordinationstest für Kinder (KTK) has been widely used in many countries with elementary school children (Krombholz, 2006; Catenassi et al., 2007, Lopes, Stodden, Bianchi, Maia \& Rodrigues, 2012; D'Hondt et al., 2014; Lopes, Santos, Moreira, Pereira \& Lopes, 2015).

In recent years, studies that have focused on the behavior of schoolchildren regarding the aspect of motor competence, highlighting evidences of a positive association of it with health-related physical fitness (Stodden et al., 2008; Cairney et al. 2010) and with the habitual level of physical activity (Stodden et al., 2008; Rivilis et al., 2011). In addition, there appears to be a consensus in the literature that motor competence interacts with physical growth and biological maturation in children and younglings (Malina et al., 2004, Lopes et al., 2012, Luz et al., 2015), but few studies have evaluated the relationship of maturational status on performance in motor coordination tests in pediatric populations (Freitas et al., 2016; Luz et al., 2016; Luz et al, 2018b) especially in conditions where the maturation effect is controlled by variables commonly associated with both the weight and the level of physical fitness related to health.

The present study aimed to analyze the effect of biological maturation on the performance in the KTK of prepubescent girls, before and after having its effect controlled by body mass index and aerobic performance.

\section{METHODS}

It is a cross-sectional descriptive study, in which the data were collected in schools in Arapiraca,
State of Alagoas, Brazil. It was conducted observing international standards for experimentation with humans (in accordance with the Declaration of Helsinki) and approved by the Research Ethics Committee of the Federal University of Alagoas (UFAL), under registration number CAAE 09200413.5.0000.5013. The schools were randomly selected, stratified by the educational system type, two public schools and two private schools. The terms of consent were given to the students, and their respective parents.

\section{Sample}

The sample consisted of 63 female children between 8.0 and 8.99 years of age. Failure to provide the informed consent, physical inability to perform physical tests or absence on the day of data collection were exclusion criteria.

\section{Anthropometry}

The study assessed stature, waist circumference, body mass and skinfolds. For all measurements, the girls were in appropriate clothing, which allowed the tests to be performed and the procedures used had as reference the recommendations brought by Lohman et. al. (1988). To evaluate the stature and the waist circumference it was used an anthropometric steel strap (Sanny Medical Starret, São Paulo, Brazil) accurate to $0.1 \mathrm{~cm}$, which was fixed to a smooth surface wall without footboard for the stature assessment. The waist circumference was measured in the moment of minimal breathing, at the midpoint between the lowest ribs and the iliac crest. The body mass was measured in a digital scale (Techiline, São Paulo, Brazil), with an accuracy of $0.1 \mathrm{~kg}$. The skinfolds were measured with a Lange adipometer (Beta Technology, Santa Cruz, California, USA), accurate to $1 \mathrm{~mm}$. Body mass index (BMI) and fat percentage estimation were calculated (Slaughter et al., 1988). From the estimate of fat percentage, the fat mass and the fat free mass were estimated.

\section{Biological maturation}

The evaluation of the biological maturation status was performed using the predicted maturity stature (PMS), by the method proposed by Khamis and Roche (1994), using measures of chronological age, stature, body mass and mean stature of the biological parents. From the PMS, the percentage of the PMS reached by the child (\% PMS) was calculated. In this study, \% PMS was expressed as z-score relative to the mean and standard deviation of the sample from the Berkeley Guidance Study, University of California (Bayer \& Bayley, 1959). For the purposes of analysis, girls with z-score $<0$ were 
considered less mature $(n=41)$ and girls with z-score $>0$ were considered more mature $(n=22)$.

\section{Motor coordination}

Gross motor coordination was assessed using the Körperkoordinationstest für Kinder (KTK), proposed by Kiphard and Schilling (1974). Its application requires an area with $4 \times 5$ meters and consists of four tasks: walking backward (WB), jumping sideways (JS), moving sideways (MS) e hopping for height (HH). A better description of the method can be found in Luz et al. (2015). The sequence of KTK tasks was uniformly applied in the following order: WB, JS, MS and $\mathrm{HH}$.

\section{Aerobic performance}

As an aerobic performance test, the 20-m shuttle run was used, proposed by the EUROFIT protocol (Commitee for the development of sports, 1998). The test consists of round-trip races, in a space of 20 meters in length marked by cones, having as reference for the rhythm of the race a sound signal, emitted by sound system. The frequency of this signal is increased every minute, which means a speed increase in the race of 0.5 $\mathrm{km} / \mathrm{h}$. The test starts with a run of $8.5 \mathrm{~km} / \mathrm{h}$. When the subject is unable to proceed, the distance accumulated at the last race is used for aerobic performance purposes (in meters). The test was performed on a different day from the KTK tasks.

\section{Data analysis}

Initially, descriptive statistics were performed, followed by Kolmogorov-Smirnov normality test. Estimation of fat mass, moving sideways and performance in the 20-m shuttle run underwent logarithmic transformation for the inferential analyzes. Subsequently, a comparison was made between groups of different maturational states by the Student t test, with chronological, anthropometric, motor coordination and aerobic performance as dependent variables. The size effect of the differences between means were calculated through the Cohen's $d$ values (Hopkins et al., 2009). Finally, ANCOVAs with BMI and aerobic performance as covariables were underwent, having the biological maturation as independent variable and the KTK tasks as dependents. All tests adopted $p<0.05$ as value of significance. Software IBM SPSS 22.0 (SPSS, Inc., Chicago, IL) was used.

\section{RESULTS}

The descriptive results are presented in table 1. The girls present an average chronological age of 8.41 years. The mean of the predicted mature stature is $162.2 \mathrm{~cm}$ and the percentage of the predicted mature stature values range from $75.6 \%$ to $88.3 \%$.

Table 2 shows the results of the biological maturation effect on chronological and anthropometric variables, KTK tasks and the 20-m shuttle run. The less maturing

Table 1. Descriptive statistics (mean, standard deviation and $95 \%$ confidence interval of the mean) for the total sample of school girls aged $8.0-8.99$ years old $(n=63)$.

\begin{tabular}{lccccc}
\hline \multirow{2}{*}{ Variable } & \multirow{2}{*}{ Unit } & \multirow{2}{*}{ Mean \pm SD } & \multirow{2}{*}{$95 \% \mathrm{Cl}$} & \multicolumn{2}{c}{ Kolmogorov-Smirnov } \\
\cline { 5 - 6 } & & & Value & p \\
\hline Chronological age & years & $8.41 \pm 0.27$ & 8.34 to 8.48 & 0.86 & 0.200 \\
Predicted mature stature (PMS) & $\mathrm{cm}$ & $162.2 \pm 5.8$ & 160.7 to 163.7 & 0.80 & 0.200 \\
Attained PMS & \%PMS & $80.4 \pm 2.6$ & 79.8 to 81.1 & 0.68 & 0.200 \\
Stature & $\mathrm{cm}$ & $130.4 \pm 5.8$ & 128.9 to 131.9 & 0.64 & 0.200 \\
Body mass & $\mathrm{kg}$ & $30.5 \pm 6.9$ & 28.8 to 32.2 & 0.85 & 0.200 \\
Body mass index & $\mathrm{Kg} . \mathrm{m}^{-2}$ & $17.8 \pm 3.3$ & 17.0 to 18.6 & 0.11 & 0.074 \\
Waist circumference & $\mathrm{cm}$ & $59.6 \pm 7.4$ & 57.7 to 61.4 & 0.87 & 0.200 \\
Fat mass & $\%$ & $28.5 \pm 6.3$ & 26.9 to 30.0 & 0.99 & 0.200 \\
Fat mass & $\mathrm{kg}$ & $9.0 \pm 4.1$ & 8.0 to 10.1 & 0.12 & $<0.05$ \\
Fat-free mass & $\mathrm{kg}$ & $21.5 \pm 3.3$ & 20.6 to 22.3 & 0.80 & 0.200 \\
Walking backward & $\#$ & $38.2 \pm 12.3$ & 35.1 to 41.3 & 0.64 & 0.200 \\
Jumping sideways & $\#$ & $30.1 \pm 9.5$ & 27.7 to 32.5 & 0.11 & 0.053 \\
Moving sideways & $\#$ & $32.0 \pm 8.3$ & 29.9 to 34.1 & 0.16 & $<0.05$ \\
Hopping for height & $\#$ & $29.8 \pm 12.6$ & 26.6 to 33.0 & 0.11 & 0.057 \\
20-m shuttle run & $\mathrm{m}$ & $266.4 \pm 125.0$ & 234.9 to 297.8 & 0.13 & $<0.05$ \\
\hline
\end{tabular}

SD (standard deviation); 95\% Cl (95\% confidence interval of the mean); \# (Counts). 
group presented lower values of stature, body mass, $\mathrm{BMI}$, waist circumference, fat percentage estimation, fat mass estimation and fat free mass estimation in comparison to the more maturing group. In contrast, in terms of physical performance, girls who were less advanced in biological maturation presented better performance in the walking backward $(t=2.706 ; p<0.01$; $d=0.70)$, moving sideways $(t=2.128 ; p<0.05 ; d=0.48)$ and hopping for height $(t=2.076 ; p<0.05 ; d=0.54)$ tasks of the KTK, as well as a better result in the 20-m shuttle run $(t=3.162 ; p<0.05 ; d=0.61)$.
Table 3 presents the effect of covariates (BMI and aerobic performance) on the different performances in KTK tasks. The BMI has no effect on the results obtained in the KTK tasks. The effect of aerobic performance in jumping sideways tasks $(F=21.520 ; p<0.001)$ and hopping for height of KTK ( $F=31.309 ; p<0.001)$ was observed. The maturational state no longer had a significant effect on the performance of KTK tasks when its effect was analyzed along with the covariates (BMI and aerobic performance).

Table 2. Descriptive statistics and results of independent $t$ test for maturity status groups including effect size.

\begin{tabular}{|c|c|c|c|c|c|c|}
\hline \multirow[b]{2}{*}{ Variable } & \multirow[b]{2}{*}{ Unit } & \multicolumn{2}{|c|}{ Contrasting somatic maturation } & \multirow[b]{2}{*}{$t(61)$} & \multirow[b]{2}{*}{$\mathbf{p}$} & \multirow[b]{2}{*}{ Cohen's d } \\
\hline & & Z-scores $<0(n=41)$ & Z-scores $>0 \quad(n=22)$ & & & \\
\hline Chronological age & Years & $8.35 \pm 0.25$ & $8.52 \pm 0.28$ & -2.386 & $<0.05$ & 0.64 \\
\hline Predicted mature stature (PMS) & $\mathrm{cm}$ & $162.6 \pm 5.8$ & $161.4 \pm 5.9$ & 0.829 & 0.411 & 0.20 \\
\hline Attained PMS & $\%$ PMS & $78.9 \pm 1.5$ & $83.2 \pm 1.8$ & -10.347 & $<0.001$ & -2.63 \\
\hline Stature & $\mathrm{cm}$ & $128.3 \pm 5.3$ & $134.5 \pm 4.7$ & -4.409 & $<0.001$ & -1.20 \\
\hline Body mass & $\mathrm{kg}$ & $26.6 \pm 3.7$ & $37.8 \pm 5.3$ & -9.816 & $<0.001$ & -2.55 \\
\hline Body mass index & $\mathrm{Kg} \cdot \mathrm{m}^{-2}$ & $16.1 \pm 1.9$ & $21.0 \pm 3.0$ & -7.820 & $<0.001$ & -2.06 \\
\hline Waist circumference & $\mathrm{cm}$ & $55.6 \pm 4.4$ & $67.0 \pm 6.1$ & -8.567 & $<0.001$ & -2.22 \\
\hline Fat mass & $\%$ & $25.9 \pm 4.3$ & $33.2 \pm 6.7$ & -5.110 & $<0.001$ & -1.36 \\
\hline Fat mass ${ }^{a}$ & $\mathrm{~kg}$ & $7.0 \pm 1.9$ & $12.8 \pm 4.4$ & -7.677 & $<0.001$ & -1.89 \\
\hline Fat-free mass & $\mathrm{kg}$ & $19.6 \pm 2.1$ & $25.0 \pm 2.0$ & -9.775 & $<0.001$ & -2.57 \\
\hline Walking backward & $\#$ & $41.1 \pm 12.1$ & $32.7 \pm 11.1$ & 2.706 & $<0.01$ & 0.70 \\
\hline Jumping sideways & \# & $31.0 \pm 10.1$ & $28.4 \pm 8.2$ & 1.013 & 0.315 & 0.27 \\
\hline Moving sideways $^{a}$ & \# & $33.4 \pm 9.0$ & $29.4 \pm 6.3$ & 2.128 & $<0.05$ & 0.48 \\
\hline Hopping for height & \# & $32.1 \pm 12.4$ & $25.4 \pm 12.1$ & 2.076 & $<0.05$ & 0.54 \\
\hline 20-m shuttle run ${ }^{a}$ & $\mathrm{~m}$ & $292.7 \pm 109.0$ & $217.3 \pm 140.2$ & 3.162 & $<0.05$ & 0.61 \\
\hline
\end{tabular}

\# (Counts); ${ }^{\text {a } L o g-t r a n s f o r m e d ~ v a l u e s ~ w e r e ~ u s e d ~ i n ~ t h e ~ a n a l y s i s . ~}$

Table 3. Descriptive statistics (mean \pm standard deviation) of KTK items by contrasting somatic maturation and results of ANCOVAs to test the effect of the covariates (BMI, 20-m shuttle-run result) and the maturity status after controlling for the covariates on the dependent variables $(n=63)$.

\begin{tabular}{lcccccc}
\hline Variable & & \multicolumn{2}{c}{ Contrasting somatic maturation } & & 20-m shuttle-run & Maturity status \\
\cline { 3 - 4 } & Unit & $\begin{array}{c}\text { Z-scores<0 } \\
(\mathbf{n}=\mathbf{4 1})\end{array}$ & $\begin{array}{c}\text { Z-scores }>\mathbf{0} \\
(\mathbf{n}=\mathbf{2 2})\end{array}$ & BMI $\mathbf{F}(\mathbf{p})$ & $\begin{array}{c}\text { 20-m } \\
\mathbf{F}(\mathbf{p})\end{array}$ & $\mathbf{F ( p )}$ \\
\hline Walking backward & $\#$ & $41.1 \pm 12.1$ & $32.7 \pm 11.1$ & 0.047 & 2.773 & 2.451 \\
Jumping sideways & $\#$ & $31.0 \pm 10.1$ & $28.4 \pm 8.2$ & 0.022 & $21.520^{*}$ & 0.546 \\
Moving sideways $^{\mathrm{a}}$ & $\#$ & $33.4 \pm 9.0$ & $29.4 \pm 6.3$ & 0.052 & 1.102 & 1.785 \\
Hopping for height & $\#$ & $32.1 \pm 12.4$ & $25.4 \pm 12.1$ & 0.604 & $31.309 *$ & 0.424 \\
\hline
\end{tabular}

BMI (body mass index); \# (counts); ${ }^{\text {a } L o g-t r a n s f o r m e d ~ v a l u e s ~ w e r e ~ u s e d ~ i n ~ t h e ~ a n a l y s i s ; ~}{ }^{*} p<0.001$. 


\section{DISCUSSION}

The results showed that the biological maturation, on its own accord, had a positive effect on body size and a negative one on the motor competence of girls, evaluated by KTK. Though, when analyzed in combination with covariates (BMI and aerobic performance), biological maturation no longer exerted a significant effect on performance in KTK tasks. The BMI did not influence the results obtained in the KTK tasks, but it was noted that the aerobic performance did, namely in the tasks of jumping sideways and hopping for height.

Recently, hierarchical multiple regression was used to assess the influence of bone age, alone or combined with stature and body mass, on fundamental motor skills and KTK tasks. In children aged 7 to 10 years, bone age alone, or associated with body size, represented only $7 \%$ to $9 \%$ of the variances in the KTK tests and in six fundamental motor skills evaluated with the Test of Gross Motor Development, in both sexes (Freitas et al., 2015). However, evidence from the literature suggests that inter-individual differences in maturation status may either positively or negatively affect performance in motor competence tests, depending on the individual and the nature of the task to be performed (Beunen et al., 1997; Katzmarzyk et al., 1997). The results found in the present study showed that girls classified as less matured had significantly lower body mass, lower amount of fat mass and fat free mass in relation to their more matured pairs. Furthermore, the KTK scores were higher in the later biological maturing groups, with a significant difference in the walking backward, moving sideways and hopping for height tests. These results confirm the trend in the literature in which the most advanced subjects in the maturational aspect present a disadvantage in motor coordination tasks (Freitas et al., 2015), which can be explained by the greater corpulence associated with the more advanced state of biological maturation.

Motor competence seems to be positively associated with the level of physical activity, physical fitness and other health-related variables in young individuals (Janssen \& Leblanc, 2010; D'Hondt et al., 2014). Girls are often assumed to be less active and less physically fit than boys during the first two decades of life, which may indicate that participation in programs of physical activity and sport could be decisive for girls in the acquisition of better motor performance, regardless of their maturational and ponderal state (Sherar, Esliger, Baxter-Jones \& Tremblay, 2007; Cumming, Standage, Gillison \& Malina, 2008). In fact, the present study revealed a positive effect of aerobic fitness on the motor coordination, results consistent with a review study published by Lubans et al. (2010) on the relationship between motor coordination and health benefits in children and adolescents, which showed that levels of motor coordination are inversely correlated with body mass but positively correlated with aerobic fitness and perceived motor competence in both cross-sectional and longitudinal studies. In addition, cardiorespiratory fitness, muscular strength, muscular endurance, anaerobic capacity and muscular power have been negatively associated, to varying degrees, with poor motor coordination in another review study performed in pediatric population (Rivilis et al., 2011).

The present study has as limitations the transversal data collection, which does not allow causal declarations, and to have used as indicator of somatic maturational the percentage of maturation predicted height reached at the moment of the study, with values of mother and father's stature obtained through self-report. The disadvantage of this technique is that an adult value is required and, consequently, maturity status can only be applied retrospectively. However, the results were, for the most part, consistent with studies that used skeletal age as an indicator of maturational status.

In conclusion, there seems to be a positive effect of biological maturation on body size, which in turn establishes a negative effect on gross motor coordination in girls, especially in tasks where body mass is displaced. Finally, the aerobic fitness effect found in the present study reinforces the importance of a greater involvement in physical-sports activities for improvement on coordinative performance in girls.

\section{REFERENCES}

Bayer LM, Bayley N. Growth diagnosis: Selected methods for interpreting and predicting development from one year to maturity. Chicago, IL: University of Chicago Press, 1959.

Beunen GP, Malina RM, Lefevre J, et al. Prediction of adult stature and noninvasive assessment of biological maturation. Med. Sci. Sports Exerc, 1997; 29; 225-230.

CairneyJ, Hay J, Veldhuizen S, et al. Comparison of VO2 maximum obtained from $20 \mathrm{~m}$ shuttle run and cycle ergometer in children with and without developmental coordination disorder. Research in Developmental Disabilities, 2010; 31; 1332-1339.

Catenassi FZ, Marques I, Bastos CB, et al. Relação entre índice de massa corporal e habilidade motora grossa em crianças de quatro a seis anos. Brazilian Journal of Sports Medicine, 2007; 13(4): 227-230.

Committee for the Development of Sports. EUROFIT: Handbook for the European test of physical fitness. Rome, Italy: Council of Europe. 1988.

Cools W, Martelaer KD, Samaey C, et al. Movement skill assessment of typically developing preschool children: a review of seven movement skill assessment tools. J Sports Sci Med, 2009; 8; 154-168. 
Cumming SP, Standage M, Gillison F, et al. Sex differences in exercise behavior during adolescence: Is biological maturation a confounding factor? Journal of Adolescent Health, 2008; 42; 480-485.

D'Hondt E, Deforche B, Gentier I, et al. A longitudinal study of gross motor coordination and weight status in children. Obesity, 2014; 22(6): 1505-1511.

Freitas DL, Lausen B, Maia JAR, et al. Skeletal Maturation, Body Size, and Motor Coordination in Youth 11-14 Years. Med Sci Sports Exerc, 2016; 48(6): 1129-1135.

Freitas DL, Lausen B, Maia JAR, et al. Skeletal maturation, fundamental motor skills and motor coordination in children 7-10 years. Journal of Sports Sciences, 2015; 33(9): 924-934.

Hopkins WG, Marshall SW, Batterham AM, et al. Progressive statistics for studies in sports medicine and exercise science. Med Sci Sports Exerc, 2009; 41(1): 3-13.

Janssen I, Leblanc AG. Systematic review of the health benefits of physical activity and fitness in school-aged children and youth. Int J Behav Nutr Phys Act, 2010; 7; 40.

Katzmarzyk PT, Malina RM, Beunen GP. The contribution of biological maturation to the strength and motor fitness of children. Annals of Human Biology, 1997; 24(6): 493505.

Khamis HJ, Roche AF. Predicting adult stature without using skeletal age: The Khamis-Roche method. Pediatrics, 94, 504-507. Erratum in: (1995). Pediatrics, 1994; 95(3): 457.

Kiphard EJ, Schilling F. Körperkoordinationstest für Kinder Body coordination test for children. Weinheim, Germany: Beltz Test GmbH. 1974.

Krombholz H. Physical performance in relation to age, sex, birth order, social class, and sports activities of preschool children. Percept Mot Skills, 2006; 102(2): 477-484.

Lohman TG, Roche AF, Martorell R. Anthropometric Standardization Reference Manual. Champaign, Illinois: Human Kinetics. 1988.

Lopes L, Santos R, Moreira C, et al. Sensitivity and specificity of different measures of adiposity to distinguish between low/high motor coordination. J Pediatr, 2015; 91(1): 44-51.
Lopes VP, Stodden DF, Bianchi MM, et al. Correlation between $\mathrm{BMI}$ and motor coordination in children. Journal of Science and Medicine in Sport, 2012; 15; 38-43.

Lubans DR, Morgan PJ, Cliff DP, et al. Fundamental movement skills in children and adolescents: review of associated health benefits. Sports Med,2010; 40(12): 1019-35.

Luz LGO, Cumming SP, Duarte JP, et al. Independent and Combined Effects of Sex and Biological Maturation on Motor Coordination and Performance in Prepubertal Children. Percept Mot Skills, 2016; 122(2): 610

Luz LGO, Seabra AFT, Santos R, et al. Association between BMI and motor coordination among children (KTK): A meta-analysis. Brazilian journal of Sports Medicine, 2015; 21(3): 230-235.

Luz LGO. et al. Biocultural Predictors of Motor Coordination Among Prepubertal Boys and Girls. Perceptual and Motor Skills, 2018a; 125(1): 21-39.

Luz LGO. et al. Multivariate Relationships among Morphology , Fitness and Motor Coordination in Prepubertal Girls. Journal of Sports Science and Medicine, 2018b; 17; 197-204.

Malina RM, Bouchard C, Bar-Or O. Growth, maturation, and physical activity. Champaign, IL: Human Kinetics 2004.

Rivilis I, Hay J, Cairney J, et al. Physical activity and fitness in children with developmental coordination disorder: a systematic review. Res Dev Disabil, 2011; 32(3): 894-910.

Robinson LE, Stodden DF, Barnett LM, et al. Motor Competence and its Effect on Positive Developmental Trajectories of Health. Sports Med, 2015; 45(9): 1273-1284.

Sherar LB, Esliger DW, Baxter-Jones ADG, et al. Age and gender differences in youth physical activity: Does physical maturity matter? Medicine and Science in Sports and Exercise, 2007; 39; 830-835.

Slaughter MH, Lohman TG, Boileau RA, et al. Skinfold equations for estimation of body fatness in children and youth. Human Biology, 1988; 60(5): 709-723.

Stodden DF, Goodway JD, Langendorfer SJ, et al. A developmental perspective on the role of motor skill competence in physical activity: An emergent relationship. Quest, 2008; 60(2): 290-306. 